\title{
Visceral hypersensitivity in endometriosis: a new target for treatment?
}

\author{
B Issa, ${ }^{1}$ T S Onon, ${ }^{2}$ A Agrawal, ${ }^{1}$ C Shekhar, ${ }^{1}$ J Morris, ${ }^{3}$ S Hamdy, ${ }^{1}$ P J Whorwell ${ }^{1}$
}

'Department of Translational Medicine, University of Manchester, Manchester, UK ${ }^{2}$ Department of Obstetrics and Gynaecology, University Hospital of South Manchester,

Manchester, UK

${ }^{3}$ Department of Medical

Statistics, University Hospital of South Manchester, Manchester, UK

\section{Correspondence to} Professor P J Whorwell, Neurogastroenterology Unit, Wythenshawe Hospital, Manchester M23 9LT, UK peter.whorwell@uhsm.nhs.uk

Revised 14 June 2011 Accepted 12 July 2011 Published Online First 25 August 2011

\begin{abstract}
Objective In women presenting to gynaecological clinics with lower abdominal pain, the cause is frequently attributed to endometriosis irrespective of whether it is found to be minimal or extensive at laparoscopy. Irritable bowel syndrome (IBS) is also common in this setting, and it was speculated that the visceral hypersensitivity associated with this condition might be amplifying the symptoms of endometriosis.
\end{abstract}

Methods Visceral sensitivity to balloon distension, symptoms and psychological status were assessed following laparoscopy in 20 women with minimal to mild endometriosis, 20 with moderate to severe endometriosis, 20 with laparoscopy negative abdominal pain and 20 asymptomatic women undergoing laparoscopic sterilisation who acted as controls, and compared with 20 women with IBS.

Results Compared with controls, patients with minimal to mild and moderate to severe endometriosis had a higher prevalence of symptoms consistent with IBS ( $0 \%$ vs $65 \%$ and $50 \%$, respectively, $p<0.001$ ) with significantly lower mean pain thresholds $(39.5 \mathrm{~mm} \mathrm{Hg}$ (95\% Cl 36.0 to 43.0$)$ vs $28.1 \mathrm{~mm} \mathrm{Hg}(95 \% \mathrm{Cl} 24.5$ to 31.6), $\mathrm{p}=0.001$ and $28.8 \mathrm{~mm} \mathrm{Hg}(95 \% \mathrm{Cl} 24.9$ to 32.6$)$, $\mathrm{p}=0.002$ ) not explained by differences in rectal compliance. Patients with laparoscopy negative pain had symptoms and visceral sensitivity similar to patients with IBS. Controls undergoing laparoscopy had normal sensitivity, indicating that the laparoscopic procedure was not inducing hypersensitivity.

Conclusion Visceral hypersensitivity is extremely common in endometriosis and could be intensifying the pain. This finding might explain why mildly affected individuals often complain of severe symptoms out of proportion to the extent of their disease. This study has introduced a completely new concept into the understanding of pain in endometriosis and could open up new opportunities for treatment.

\section{INTRODUCTION}

We have previously shown that patients with irritable bowel syndrome (IBS) frequently have a wide range of non-colonic symptoms such as backache and lethargy as well as a number of musculoskeletal, urological and gynaecological problems. ${ }^{1}$ These can result in patients being referred to the wrong specialty if the gastrointestinal symptoms are not severe or a non-colonic feature is especially prominent. This is a particular problem in gynaecological clinics as women with IBS often have dysmenorrhoea and dyspareunia, ${ }^{12}$ making referral to this setting even more likely. We have also shown that patients with IBS are over-represented

\section{Significance of this study}

What is already known about this subject?

- The severity of symptoms in patients with minimal to mild endometriosis can be out of proportion to the laparoscopic findings.

- The reason for this observation is unknown.

- Such individuals are notoriously refractory to a whole range of gynaecological interventions which can also be associated with significant adverse effects.

What are the new findings?

- This study has shown that visceral hypersensitivity is common in patients with endometriosis and especially those with minimal to mild disease.

- This abnormality might be the underlying mechanism that explains the paradoxical discrepancy between symptoms and extent of disease.

\section{How might it impact on clinical practice in} the foreseeable future?

- Specifically targeting this abnormality might offer a completely novel way of managing this condition without the need for hormonal manipulation or the consideration of various surgical options.

in gynaecological clinics ${ }^{3}{ }^{4}$ with outcomes being less favourable in these individuals, ${ }^{3}$ and it is also noteworthy that hysterectomy rates are much higher in patients with IBS. ${ }^{5}$

In women presenting to gynaecological practice with abdominal or pelvic pain, the investigation frequently includes laparoscopy and endometriosis is not an unusual finding. This is perhaps not surprising as it is a common condition and can even be found in up to $10 \%$ of asymptomatic individuals. $^{6-10}$ If the condition is severe it seems reasonable to conclude that it causes symptoms, but if it is mild this may not be such a safe conclusion. However, in patients with lower abdominal pain it is common gynaecological practice to attribute the pain to endometriosis, whatever the severity. This may be a critically important factor in a patient who actually has IBS and is being referred to the gynaecologist because of coincidental gynaecological symptoms such as heavy periods or dyspareunia, especially as the latter is a common feature in IBS. ${ }^{1}$ In such a situation, laparoscopically 
minimal endometriosis might wrongly be implicated as the cause of the pain.

There are at least two potential ways in which IBS and endometriosis might be confused. First, it has been known for many years that IBS is frequently associated with excessive sensitivity to balloon distension of the gut, which is usually referred to as visceral hypersensitivity, ${ }^{11} 12$ to the extent that it has even been suggested by some that it might be a biological marker for the condition. ${ }^{13}$ Consequently, it may be possible that, in an individual with IBS and visceral hypersensitivity, a small area of endometriosis which would not normally be perceived as painful might become painful as a result of amplification of any subliminal pain associated with the lesion. Alternatively, the pain in a patient with minimal endometriosis might be due to coexisting IBS with the endometriosis being a coincidental finding which is not directly causing any problems. Indeed, there are reports of IBS being associated with endometriosis, ${ }^{14}{ }^{15}$ but these observations do not answer the question of whether this is due to symptom amplification or the coincidence of two separate conditions. Either of these two hypotheses might explain why it is frequently reported that the intensity of the pain in endometriosis appears to bear little or no relationship to the severity of disease as determined by laparoscopy, ${ }^{16}$ with mildly affected patients in particular often complaining of the most pain. In such individuals the finding of mild endometriosis could currently lead to a series of pharmacological treatments such as hormonal manipulation or, in the absence of a response, some form of surgical intervention. We have speculated that visceral hypersensitivity might be contributing to the pain experienced by women with endometriosis and, when the condition is mild, may lead to inappropriate treatment. The purpose of this study was therefore to assess the prevalence of visceral hypersensitivity in patients with varying degrees of endometriosis as well as documenting symptoms consistent with a diagnosis of IBS.

\section{METHODS}

Patients attending the gynaecological department for the laparoscopic investigation of abdominal pain and found to have endometriosis were eligible for the study. Those without any evidence of other coexistent gynaecological disease had their endometriosis carefully documented and staged according to the revised American Fertility Society (rAFS) guidelines ${ }^{17} 18$ which recommend reporting the laparoscopic findings as minimal, mild, moderate or severe based on a points system that takes into account the size and site of the lesions and the extent of adnexal adhesions and cul-de-sac obliteration. The rAFS guidelines were selected because they are the most widely accepted system, although it has to be acknowledged that all staging systems for endometriosis are subjective and therefore prone to interobserver variation. Patients were then divided into two groups consisting of 20 with minimal to mild endometriosis and 20 with moderate to severe disease, and these were compared with three other groups of women: (1) 20 patients attending for diagnostic laparoscopy for the investigation of abdominal pain and found to have a normal pelvis formed a group of individuals with laparoscopically negative abdominal pain; (2) 20 patients attending for laparoscopic sterilisation were included as a group of laparoscopically normal healthy volunteers in order to investigate the possibility that laparoscopy might lead to visceral sensitisation; and (3) 20 women with a firm diagnosis of uncomplicated IBS although, for ethical reasons, we were not allowed to undertake laparoscopy in these individuals. Participants taking long-term medication likely to affect visceral sensation were excluded as were those unable to stop taking for a period of $48 \mathrm{~h}$ any other medication that could possibly interfere with the results (eg, analgesics, antispasmodics, antidepressants or non-steroidal antiinflammatory preparations). All barostat tests were carried out in the luteal phase of the menstrual cycle in those individuals with regular periods at least 4 weeks after their laparoscopy.

All subjects completed the following questionnaires: the Hospital Anxiety Depression (HAD) Scale, ${ }^{19}$ the ROME III diagnostic questionnaire, ${ }^{20}$ the Irritable Bowel Syndrome Symptom Severity Score (IBS SSS) ${ }^{21}$ and the Non-Colonic Symptom and Quality of Life Score. ${ }^{22}$ The only validated symptom severity scoring system for endometriosis was published after the start of this study ${ }^{23}$ and therefore not used. However, the following symptoms and other features associated with endometriosis were recorded: pain severity with periods graded on a scale of $0-10$, pain on intercourse graded on a scale of $0-10$, pain severity between periods graded on a scale of $0-10$, parity, difficulty conceiving, absence from work due to pain, continuing at work despite pain and a family history of endometriosis. Those items that were scored $0-10$ were combined into an overall endometriosis pain score $(0-30)$ and used for the analysis. Any other relevant medical data were also recorded.

Rectal sensitivity testing is a well-described technique ${ }^{24}$ which was performed after an overnight fast and a fleet enema with all participants being asked to refrain from smoking and the consumption of caffeine for $24 \mathrm{~h}$. Sensitivity was assessed using a barostat technique with tracking which has been described in detail elsewhere. ${ }^{25}$ A flaccid barostat bag was placed in the rectum and the participant allowed to rest for $1 \mathrm{~h}$. Isobaric phasic distensions were then performed (increments of $4 \mathrm{~mm} \mathrm{Hg}$ for 1 min with 1 min return to basal operating pressure in between) up to a maximum pressure of $50 \mathrm{~mm} \mathrm{Hg}$. At each step the volume of the bag was measured in order to build dynamic compliance curves. In addition, static compliance was calculated by taking the mean value of the volume of the barostat at a pressure of $20 \mathrm{~mm} \mathrm{Hg}$. The patient was questioned at each inflation step ( $4 \mathrm{~mm} \mathrm{Hg}$ ) in order to find the amount of distension associated with the first sensation of distension, sensation of stool and sensation of pain. During each inflation above basal operating pressure levels, $30 \mathrm{~s}$ after commencement of the inflation, patients were prompted to indicate on a standard proforma what sensations they were experiencing. Tracking, which is a technique which makes the inflations unpredictable to the subject and thus minimises bias, was commenced when the subject first experienced moderate or severe pain. Subsequent distensions were then adjusted up or down, depending on the subject's response to the previous distension. If the subject reported pain on the previous trial, the next distension was decreased or kept the same. If the subject reported no pain on the previous trial, the next distension was increased or kept the same. In order to make the changes in the amount of distension unpredictable, a random numbers algorithm was used to determine whether to decrease the amount of distension or keep it the same following a painful test period. The sensory threshold was then determined by averaging the intensity over a series of tracking trials of the threshold. The distension test was discontinued after 12 distension trials or after reaching the upper limit of $50 \mathrm{~mm} \mathrm{Hg}$ without pain sensation. At any time the patient could choose to terminate the distension session for any reason by pressing the 'panic button'. The investigator could also stop the test if it was considered undesirable to continue for any reason.

\section{Power calculation}

Based on previous data collected in our laboratory on visceral sensation using rectal sensitivity testing, it was estimated that 
this study would require 20 patients in each endometriosis and control group in order to have an $80 \%$ power of detecting a difference in sensitivity of $10 \mathrm{~mm} \mathrm{Hg}$ between groups at a significance level of $5 \%$.

\section{Statistical analysis}

Comparisons between patient groups were carried out using one-factor ANOVA followed by the Scheffe multiple comparison test. Anxiety and depression scores followed a non-normal distribution and, for these variables, the non-parametric KruskalWallis test was used followed by the Mann-Whitney $U$ test with Bonferroni correction. The influence of anxiety and depression on group comparisons was assessed by analyses of covariance. The results of analyses of covariance, when adjusted for anxiety and depression, did not differ from those from the simple ANOVA and are therefore not reported. The relationship between pain thresholds and IBS severity scores as well as endometriosis pain scores were assessed using the Pearson correlation coefficient. Pain thresholds were compared in patients with Rome positive and Rome negative endometriosis using the independent $t$ test. The same statistics were used for comparing the endometriosis pain scores in patients with minimal to mild and moderate to severe endometriosis.

\section{RESULTS}

Table 1 shows the demographic and clinical data for each of the groups, whether the patients fulfilled the Rome criteria for IBS and, if so, the type (constipation, diarrhoea, mixed or unclassified). Also shown are the scores for anxiety, depression, IBS severity and quality of life.

Table 2 shows the results of barostat testing for sensory thresholds and compliance. All groups were comparable with respect to age but there were significant differences in other variables. As might be expected, the healthy controls did not meet the criteria for IBS and had sensory thresholds within the normal range. ${ }^{24}$

In comparison with the controls, all the other groups had a higher prevalence of symptoms consistent with IBS as well as elevated IBS symptom severity scores. With regard to pain thresholds, all groups except those patients with abdominal pain without any other abnormality had hypersensitivity similar to that seen in IBS, which was significantly different from that seen in controls. The thresholds for first sensation and stool sensation showed the same trends. Figure 1 shows the mean values and individual data for pain thresholds for all groups studied. There was a highly significant difference in the thresholds for pain in the endometriosis groups compared with the controls ( $p=0.001$ and $p=0.002$, respectively, for minimal to mild and moderate to severe endometriosis). It is important to note that the controls who had undergone laparoscopy for reasons other than pain had normal sensitivity (table 1 and figure 1). This indicates that the process of having a laparoscopic procedure is not in itself the cause of the hypersensitivity observed in the other groups. There were no significant differences between the groups with respect to rectal compliance.

A $90 \%$ normal reference range for sensitivity was derived for the laparoscopic controls and found to be 31-48 $\mathrm{mm} \mathrm{Hg}$. Based on this, $60 \%(12 / 20)$ of the patients with minimal to mild endometriosis and $65 \%(13 / 20)$ of those with moderate to severe endometriosis had pain thresholds below the lower limit of this range. In addition, $75 \%(15 / 20)$ of the patients with IBS and $45 \%$ (9/20) of the patients with laparoscopy negative pain had sensitivity below this range.

With regard to IBS severity and pain thresholds in all groups, there was only a significant correlation between severity and pain threshold in the moderate to severe endometriosis group $(r=-0.47 ; p=0.036)$. When patients with endometriosis were divided into those fulfilling or not fulfilling the Rome criteria for IBS, there was no significant difference in the mean pain thresholds for the minimal to mild cases. However, among the patients with moderate to severe endometriosis, the Romepositive patients had significantly lower mean pain thresholds than the Rome-negative individuals $(24.6 \mathrm{~mm} \mathrm{Hg}$ vs $33.8 \mathrm{~mm} \mathrm{Hg}$; $=0.008$ ).

With regard to the endometriosis pain scores, there was no significant difference between patients with minimal to mild disease and those with moderate to severe disease (mean score 11.00 vs $11.6 ; p=0.75$ ). Furthermore, there was no significant correlation between the endometriosis pain scores and pain thresholds for any of the endometriosis groups.

\section{DISCUSSION}

This study has introduced a completely new concept into the understanding of pain in endometriosis. It appears that visceral

Table 1 Demographic and clinical data

\begin{tabular}{|c|c|c|c|c|c|c|}
\hline & $\begin{array}{l}\text { Laparoscopy } \\
\text { controls }(n=20)\end{array}$ & $\begin{array}{l}\text { Minimal to mild } \\
\text { endometriosis } \\
(n=20)\end{array}$ & $\begin{array}{l}\text { Moderate to severe } \\
\text { endometriosis } \\
(n=20)\end{array}$ & $\begin{array}{l}\text { Laparoscopy negative } \\
\text { abdominal pain } \\
(\mathrm{n}=20)\end{array}$ & $\begin{array}{l}\text { Irritable bowel } \\
\text { syndrome (IBS) } \\
(n=20)\end{array}$ & $\begin{array}{l}\text { Comparison } \\
\text { of groups }\end{array}$ \\
\hline Age, mean (range) & $35.2(23-46)$ & $31.1(19-48)$ & $36.0(22-47)$ & $35.0(22-48)$ & $34.3(20-54)$ & $p=0.37$ \\
\hline Rome positive (n) & 0 & $13^{*}$ & $11^{*}$ & $17^{*}$ & $20^{*}$ & $\mathrm{p}<0.001$ \\
\hline IBS-D & 0 & 1 & 0 & 1 & 1 & \\
\hline IBS-C & 0 & 6 & 5 & 11 & 16 & \\
\hline IBS-mixed & 0 & 4 & 1 & 4 & 3 & \\
\hline IBS-U & 0 & 2 & 5 & 1 & 0 & \\
\hline $\begin{array}{l}\text { Anxiety score, } \\
\text { median (range) }\end{array}$ & $6.0(1-17)$ & $8.5(4-14) \dagger$ & $7.5(1-15)$ & $8.0(4-18) \dagger$ & $8.0(1-15)$ & $p=0.04$ \\
\hline $\begin{array}{l}\text { Depression score, } \\
\text { median (range) }\end{array}$ & $3.0(0-16)$ & $4.0(1-14)$ & $3.0(0-18)$ & $5.0(0-13)$ & $4.0(0-17)$ & $\mathrm{p}=0.13$ \\
\hline $\begin{array}{l}\text { IBS severity score, } \\
\text { mean (range) }\end{array}$ & $50.2(0-149)$ & $237.7(66-423) \dagger \ddagger$ & $204.1(0-420) \dagger \ddagger$ & $251.8(120-420) \dagger \neq$ & $340.0(207-465) \dagger$ & $\mathrm{p}<0.001$ \\
\hline $\begin{array}{l}\text { Quality of life score, } \\
\text { mean (range) }\end{array}$ & $384.3(75-454)$ & $335.4(120-627)$ & $333.9(192-456)$ & $307.1(133-425)$ & $317.8(134-584)$ & $p=0.10$ \\
\hline
\end{tabular}

${ }^{*}$ Comparison with controls: $p<0.001$.

†Comparison with controls: $p<0.05$

$\neq$ Comparison with IBS: $p<0.05$. 
Table 2 Physiological data

\begin{tabular}{|c|c|c|c|c|c|c|}
\hline & $\begin{array}{l}\text { Laparoscopy } \\
\text { controls }(n=20)\end{array}$ & $\begin{array}{l}\text { Minimal to mild } \\
\text { endometriosis } \\
(\mathrm{n}=20)\end{array}$ & $\begin{array}{l}\text { Moderate to severe } \\
\text { endometriosis } \\
(n=20)\end{array}$ & $\begin{array}{l}\text { Laparoscopy negative } \\
\text { abdominal pain } \\
(\mathrm{n}=\mathbf{2 0})\end{array}$ & $\begin{array}{l}\text { Irritable bowel } \\
\text { syndrome (IBS) } \\
\text { (n=20) }\end{array}$ & $\begin{array}{l}\text { Comparison } \\
\text { of groups }\end{array}$ \\
\hline $\begin{array}{l}\text { First sensation }(\mathrm{mm} \mathrm{Hg}) \\
\text { mean }(95 \% \mathrm{Cl})\end{array}$ & 19.2 (16.3 to 22.1$)$ & $15.3(14.0$ to 166$)$ & 15.5 (13.6 to 174$)$ & $16.3(14.1$ to 18.5$)$ & $12.6(10.8 \text { to } 14.4)^{*}$ & $\mathrm{p}<0.001$ \\
\hline $\begin{array}{l}\text { Stool sensation }(\mathrm{mm} \mathrm{Hg}) \text {, } \\
\text { mean }(95 \% \mathrm{Cl})\end{array}$ & 32.6 (28.6 to 36.6$)$ & 25.9 (23.6 to 28.2 ) & 26.0 (21.9 to 30.1$)$ & 28.0 (22.8 to 33.2 ) & $24.3(20.4 \text { to } 28.3)^{* *}$ & $p=0.027$ \\
\hline $\begin{array}{l}\text { Pain threshold }(\mathrm{mm} \mathrm{Hg}) \text {, } \\
\text { mean }(95 \% \mathrm{Cl})\end{array}$ & 39.5 (36.0 to 43.0$)$ & $28.1(24.5 \text { to } 31.6)^{* * * *}$ & $28.8(24.9 \text { to } 32.6)^{* * * *}$ & 32.7 (28.8 to 36.6$)$ & $25.4(21.7 \text { to } 29.3)^{*}$ & $\mathrm{p}<0.001$ \\
\hline $\begin{array}{l}\text { Dynamic compliance, } \\
\text { mean }(95 \% \mathrm{Cl})\end{array}$ & 7.1 (5.7 to 8.6$)$ & 7.1 (5.9 to 8.2$)$ & $8.4(7.3$ to 9.6$)$ & $8.3(6.2$ to 10.4$)$ & 9.1 (7.8 to 10.5$)$ & $\mathrm{p}=0.18$ \\
\hline
\end{tabular}

Comparison with controls: ${ }^{*} \mathrm{p}<0.001 ;{ }^{* *} \mathrm{p}=0.05 ;{ }^{* * *} \mathrm{p}=0.001 ;{ }^{* * * *} \mathrm{p}=0.002$.

hypersensitivity is common in patients with this condition and may be significantly contributing to their symptoms. This finding could therefore have major implications with regard to the treatment of endometriosis.

In the laparoscopically normal healthy volunteers visceral sensory thresholds were within normal limits whereas the patients with IBS, as might be anticipated, showed visceral hypersensitivity. It would be expected that at least a proportion of patients with laparoscopically negative abdominal pain might actually have IBS, and this was suggested by the fact that $70 \%$ fulfilled the Rome III criteria for the condition. Consequently, this group also had sensory thresholds that did not differ significantly from those of the individuals with IBS. Irrespective of the extent of their disease, the patients with endometriosis also exhibited visceral sensitivity in the range seen in patients with IBS, although it should be noted that the prevalence of constipation was somewhat higher in patients with IBS than in those with endometriosis so they were not exactly comparable. However, the most notable finding was that there was a highly significant difference in thresholds for pain between the patients with endometriosis and controls, the patients with endometriosis exhibiting hypersensitivity. Furthermore, the proportion of these patients who exhibited visceral hypersensitivity was $60 \%$ and $65 \%$ for minimal to mild endometriosis and moderate to severe endometriosis, respectively, and this is similar to that reported in the literature for IBS and what was observed in the

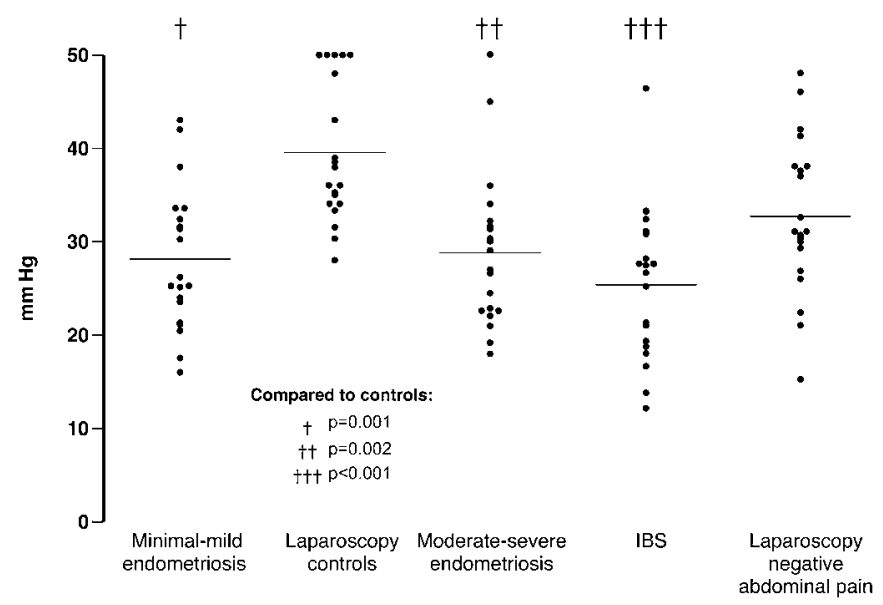

Figure 1 Comparison of individual sensory thresholds and group means between laparoscopy controls and patients with minimal to mild endometriosis, moderate to severe endometriosis, laparoscopy negative abdominal pain and irritable bowel syndrome (IBS). patients with IBS included in this study. The thresholds for first sensation and stool sensation showed a similar trend to that for pain but did not reach significance, which is not unusual in studies of this type. Moreover, the first sensation and stool sensation thresholds are not considered to be as discriminatory as the pain threshold and therefore are not even subjected to tracking in the testing procedure. It is also of interest to note that there were no differences in the endometriosis pain scores between those with minimal to mild disease and the more severely affected individuals. This is entirely consistent with the literature as well as clinical experience, and again serves to emphasise the problem of the relationship between symptomatology and extent of disease in this condition.

The observation that laparoscopy did not appear to result in increased visceral sensitivity in the healthy volunteers makes the possibility that this procedure might be the cause of this abnormality in the other groups highly unlikely. However, there are at least two other possible explanations for the hypersensitivity seen in the patients with endometriosis. First, it may be that endometriosis of any extent might sensitise the contents of the peritoneal cavity including the gut in some way or, alternatively, that these patients actually had a generalised visceral hypersensitivity associated with IBS, especially as so many of these patients with endometriosis fulfilled the Rome criteria for IBS. To our knowledge, there are no data on whether endometriosis can sensitise the peritoneal cavity, although our observations that patients with Rome-negative endometriosis with more severe disease were significantly less sensitive than Romepositive individuals suggest that endometriosis on its own does not lead to rectal sensitisation. In addition, it is not known whether patients with IBS with rectal hypersensitivity have increased sensitivity which extends to the peritoneum. However, it has been shown that the hypersensitivity in patients with IBS is not confined to the rectum and can affect the whole gastrointestinal system. ${ }^{26}$ Furthermore, hypersensitivity beyond the confines of the gut in IBS is suggested by the findings of auditory ${ }^{27} 28$ and visual ${ }^{29}$ hypersensitivity in these individuals and the coexistence of other syndromes such as fibromyalgia. ${ }^{30}$ Furthermore, it is noteworthy that these patients frequently also have bladder symptoms ${ }^{31}$ and, on testing, have been shown to have urodynamic abnormalities ${ }^{32}$ which again emphasises the diffuse nature of IBS. There is therefore some evidence to suggest that IBS is associated with hypersensitivity extending beyond the confines of the gut, which supports the notion that patients with such a generalised hypersensitivity may be more likely to report symptoms from an inflamed area, wherever that might be. Therefore, in an individual with generalised hypersensitivity, if they have an 
inflammatory process in both the peritoneal cavity (endometriosis) and the gastrointestinal mucosa (IBS), they may well report symptoms from both anatomical sites. This makes it somewhat less likely that our observations represent a coincidental finding of endometriosis in patients with IBS seeking healthcare, although this remains a possibility which would still have profound implications with regard to treatment, especially in individuals with minimal disease.

The role of inflammation in endometriosis and IBS is a further aspect that merits discussion. Ever since Chaudhary and Truelove first described the occurrence of IBS following a dysenteric infection, ${ }^{33}$ evidence has continued to emerge suggesting that there might be a persistent low-grade inflammatory response within the gastrointestinal mucosa of at least some cases. ${ }^{34-39}$ It is therefore noteworthy that there has been an increasing amount of attention on inflammation in relation to endometriosis, ${ }^{40-43}$ and in some instances the research on inflammation in IBS almost completely mirrors that which is being undertaken in endometriosis. For example, there have been reports of mast activation in both conditions and that these activated mast cells are in close proximity to nerve fibres, ${ }^{44} 45$ and also that Toll-like receptors may also be involved in the inflammatory process. ${ }^{46} 47$ Thus, the evaluation of various inflammatory markers in laparosopically obtained serosal biopsies in these patients with visceral hypersensitivity would be of considerable interest, but was obviously beyond the scope of this study.

Whatever the cause of the visceral hypersensitivity identified in these patients with endometriosis, it may open up new treatment options especially in those with severe symptoms despite apparently mild disease. Although it is now recognised that IBS is a multifactorial disorder, visceral hypersensitivity is thought to be a sufficiently important contributing feature that it is viewed as a logical target for pharmacological intervention. As a consequence, drugs that could possibly have an effect on this pathophysiological parameter such as pregabalin ${ }^{48}$ and ketotifen ${ }^{49}$ are being assessed, and it is thought that the tricyclic antidepressants, which are often very effective in IBS, at least partly mediate their benefit by reducing the sensitivity of the gut. ${ }^{5} 51$ Consequently, in patients with mild endometriosis, a trial of one of these modulators of visceral sensitivity may be worthy of consideration before embarking on more aggressive treatment, particularly surgery. Obviously, the situation is far more complicated in the more severe forms of the disease but, even in these patients, attempts to reduce hypersensitivity in conjunction with other forms of treatment might be a viable option. The question of whether the use of desensitising agents should be undertaken empirically or only after sensitivity testing would need to be answered by further research. In addition, it would be advisable to treat any symptoms of IBS, especially if the patient meets the criteria for this condition and their complaints seem out of proportion to the laparoscopic findings.

Acknowledgements We are grateful to all the consultant staff in the Department of Obstetrics and Gynaecology at the University Hospital of South Manchester NHS Foundation Trust for allowing us to study their patients.

Funding PJW has served as an advisory board member or received research funding from the following pharmaceutical companies: Novartis Pharmaceuticals, Glaxo SmithKline, Pfizer Global R\&D, Solvay Pharmaceuticals, Rotta Research, Proctor and Gamble, Danone Research, Astellas Pharma, Ironwood Pharmaceuticals, Sucampo Pharmaceuticals, Almirall Pharma, Movetis UK, Norgine and Chr Hansen, Boehringer-Ingelheim, Heel GmbH.

Competing interests None

Patient consent Obtained.

Ethics approval The study was approved by the South Manchester Research Committee and all participants gave written informed consent.
Contributors Original hypothesis: PJW; design and supervision of the study: PJW, SH, TSO; conduct of the study: BI, CS and AA; analysis of data: JM; writing and revision of the paper: all authors.

Provenance and peer review Not commissioned; externally peer reviewed.

\section{REFERENCES}

1. Whorwell PJ, McCallum M, Creed FH, et al. Non-colonic features of irritable bowel syndrome. Gut 1986;27:37-40.

2. Guthrie $\mathbf{E}$, Creed FH, Whorwell PJ. Severe sexual dysfunction in women with the irritable bowel syndrome: comparison with inflammatory bowel disease and duodena ulceration. BMJ (Clin Res Ed) 1987:5:577-8.

3. Prior A, Whorwell PJ. Gynaecological consultation in patients with the irritable bowel syndrome. Gut 1989;30:996-8.

4. Prior A, Wilson K, Whorwell PJ, et al. Irritable bowel syndrome in the gynecologica clinic. Survey of 798 new referrals. Dig Dis Sci 1989;34:1820-4.

5. Longstreth GF, Yao JF. Irritable bowel syndrome and surgery: a multivariable analysis. Gastroenterology 2004;126:1665-73.

6. Wykes CB, Clark TJ, Khan KS. Accuracy of laparoscopy in the diagnosis of endometriosis: a systematic quantitative review. BJOG 2004:111:1204-12.

7. Cramer DW, Missmer SA. The epidemiology of endometriosis. Ann N Y Acad Sci 2002;955:11-22; discussion 34-6, 396-406

8. Giudice LC, Kao LC. Endometriosis. Lancet 2004:364:1789-99.

9. Vigano P, Parazzini F, Somigliana E, et al. Endometriosis: epidemiology and aetiological factors. Best Pract Res Clin Obstet Gynaecol 2004;18:177-200.

10. Schindler AE. Pathophysiology, diagnosis and treatment of endometriosis. Minerva Ginecol 2004;56:419-35.

11. Azpiroz F, Bouin M, Camilleri M, et al. Mechanisms of hypersensitivity in IBS and functional disorders. Neurogastroenterol Motil 2007;19(1 Suppl):62-88.

12. Ritchie J. Pain from distension of the pelvic colon by inflating a balloon in the irritable colon syndrome. Gut 1973;14:125-32.

13. Mertz H, Naliboff B, Munakata J, et al. Altered rectal perception is a biological marker of patients with irritable bowel syndrome. Gastroenterology 1995;109:40-52.

14. Meurs-Szojda MM, Mijatovic V, Felt-Bersma RJ, et al. Irritable bowel syndrome and chronic constipation in patients with endometriosis. Colorectal Dis 2011:13:67-71.

15. Seaman HE, Ballard KD, Wright JT, et al. Endometriosis and its coexistence with irritable bowel syndrome and pelvic inflammatory disease: findings from a national case-control study-Part 2. Br J Obstet Gynaecol 2008;115:1392-6.

16. Kennedy S, Bergqvist $A$, Chapron $C$, et al. ESHRE guideline for the diagnosis and treatment of endometriosis. Hum Reprod 2005:20:2698-704.

17. Anon. Revised American Society for Reproductive Medicine classification of endometriosis: 1996. Fertil Steril 1997;67:817-21.

18. Anon. Revised American Fertility Society classification of endometriosis: 1985. Fertil Steril 1985; $\mathbf{4 3 : 3 5 1 - 2}$

19. Zigmond AS, Snaith RP. The hospital anxiety and depression scale. Acta Psychiatr Scand 1983:67:361-70.

20. Thompson WG, Longstreth GF, Drossman DA, et al. Functional bowel disorders and functional abdominal pain. Gut 1999;45(Suppl 2):|l43-7.

21. Francis CY, Morris $\mathrm{J}$, Whorwell PJ. The irritable bowel severity scoring system: a simple method of monitoring irritable bowel syndrome and its progress. Aliment Pharmacol Ther 1997:11:395-402.

22. Gonsalkorale WM, Houghton LA, Whorwell PJ. Hypnotherapy in irritable bowe syndrome: a large-scale audit of a clinical service with examination of factors influencing responsiveness. Am J Gastroenterol 2002:97:954-61.

23. Deal LS, DiBenedetti DB, Williams VS, et al. The development and validation of the daily electronic Endometriosis Pain and Bleeding Diary. Health Qual Life Outcomes 2010;8:64

24. Whitehead WE, Delvaux M. Standardization of barostat procedures for testing smooth muscle tone and sensory thresholds in the gastrointestinal tract. The Working Team of Glaxo-Wellcome Research, UK. Dig Dis Sci 1997;42:223-41.

25. Agrawal A, Houghton LA, Lea R, et al. Bloating and distention in irritable bowel syndrome: the role of visceral sensation. Gastroenterology 2008:134:1882-9.

26. Francis CY, Whorwell PJ. Enhanced sensitivity of the whole gut in patients with irritable bowel syndrome. Gastroenterology 1995:108:A601.

27. Blomhoff S, Jacobsen MB, Spetalen S, et al. Perceptual hyperreactivity to auditory stimuli in patients with irritable bowel syndrome. Scand J Gastroenterol 2000;35:583-9.

28. Andresen V, Bach DR, Poellinger A, et al. Brain activation responses to subliminal or supraliminal rectal stimuli and to auditory stimuli in irritable bowel syndrome. Neurogastroenterol Motil 2005;17:827-37.

29. Carruthers HR, Morris J, Tarrier N, et al. Reactivity to images in health and irritable bowel syndrome. Aliment Pharmacol Ther 2010;31:131-42.

30. Barton A, Pal B, Whorwell PJ, et al. Increased prevalence of sicca complex and fibromyalgia in patients with irritable bowel syndrome. Am J Gastroenterol 1999;94:1898-901.

31. Francis CY, Duffy JN, Whorwell PJ, et al. High prevalence of irritable bowel syndrome in patients attending urological outpatient departments. Dig Dis Sci 1997:42:404-7.

32. Whorwell PJ, Lupton EW, Erduran D, et al. Bladder smooth muscle dysfunction in patients with irritable bowel syndrome. Gut 1986;27:1014-17. 
33. Chaudhary NA, Truelove SC. The irritable colon syndrome. A study of the clinical features, predisposing causes, and prognosis in 130 cases. $0 \mathrm{~J} \mathrm{Med}$ 1962;31:307-22.

34. Ford AC, Talley NJ. Mucosal inflammation as a potential etiological factor in irritable bowel syndrome: a systematic review. J Gastroenterol 2011;46:421-31.

35. Ortiz-Lucas M, Saz-Peiro P, Sebastian-Domingo JJ. Irritable bowel syndrome immune hypothesis. Part one: the role of lymphocytes and mast cells. Rev Esp Enferm Dig 2010;102:637-47.

36. Ortiz-Lucas M, Saz-Peiro P. Sebastian-Domingo JJ. Irritable bowel syndrome immune hypothesis. Part two: the role of cytokines. Rev Esp Enferm Dig 2010;102:711-17.

37. Ohman L, Simrén M. Pathogenesis of IBS. role of inflammation, immunity and neuroimmune interactions. Nat Rev Gastroenterol Hepatol 2010; 7:163-73.

38. Spiller R, Garsed K. Infection, inflammation, and the irritable bowel syndrome. Dig Liver Dis 2009:41:844-9.

39. Gwee KA, Leong YL, Graham C, et al. The role of psychological and biological factors in postinfective gut dysfunction. Gut 1999;44:400-6.

40. Agic $\mathbf{A}, \mathrm{Xu} \mathrm{H}$, Finas $\mathrm{D}$, et al. Is endometriosis associated with systemic subclinical inflammation? Gynecol Obstet Invest 2006;62:139-47.

41. Sharpe-Timms KL, Nabli H, Zimmer RL, et al. Inflammatory cytokines differentially up-regulate human endometrial haptoglobin production in women with endometriosis. Hum Reprod 2010;25:1241-50.

42. Berbic M, Fraser IS. Regulatory T cells and other leukocytes in the pathogenesis of endometriosis. J Reprod Immunol 2011;88:149-55.
43. Kyama CM, Debrock S, Mwenda JM, et al. Potential involvement of the immune system in the development of endometriosis. Reprod Biol Endocrinol 2003;1:123.

44. Barbara G, Stanghellini V, De Giorgio R, et al. Activated mast cells in proximity to colonic nerves correlate with abdominal pain in irritable bowel syndrome. Gastroenterology 2004;126:693-702

45. Anaf V, Chapron C, El Nakadi I, et al. Pain, mast cells, and nerves in peritoneal, ovarian, and deep infiltrating endometriosis. Fertil Steril 2006;86:1336-43.

46. Barbara G. Editorial: toll-like receptor expression in irritable bowel syndrome: on the alert for a microbial threat? Am J Gastroenterol 2011:106:337-9.

47. Kajihara H, Yamada Y, Kanayama S, et al. New insights into the pathophysiology of endometriosis: from chronic inflammation to danger signal. Gynecol Endocrinol 2011;27:73-9.

48. Houghton LA, Fell C, Whorwell PJ, et al. Effect of a second-generation alpha2delta ligand (pregabalin) on visceral sensation in hypersensitive patients with irritable bowel syndrome. Gut 2007:56:1218-25.

49. Klooker TK, Braak B, Koopman KE, et al. The mast cell stabiliser ketotifen decreases visceral hypersensitivity and improves intestinal symptoms in patients with irritable bowel syndrome. Gut 2010;59:1213-21.

50. Mertz H, Morgan V, Tanner G, et al. Regional cerebral activation in irritable bowe syndrome and control subjects with painful and nonpainful rectal distention. Gastroenterology 2000;118:842-8.

51. Thoua NM, Murray CD, Winchester WJ, et al. Amitriptyline modifies the visceral hypersensitivity response to acute stress in the irritable bowel syndrome. Aliment Pharmacol Ther 2009;29:552-60.

Advancing Postgraduates. Enhancing Healthcare.

The Postgraduate Medical Journal is dedicated to advancing the understanding of postgraduate medical education and training

- Acquire the necessary skills to deliver the highest possible standards of patient care

- Develop suitable training programmes for your trainees

- Maintain high standards after training ends

Published on behalf of the fellowship for Postgraduate Medicine

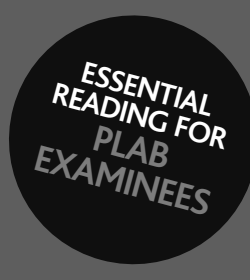

FOR MORE DETAILS OR TO SUBSCRIBE,

VISIT THE WEBSITE TODAY

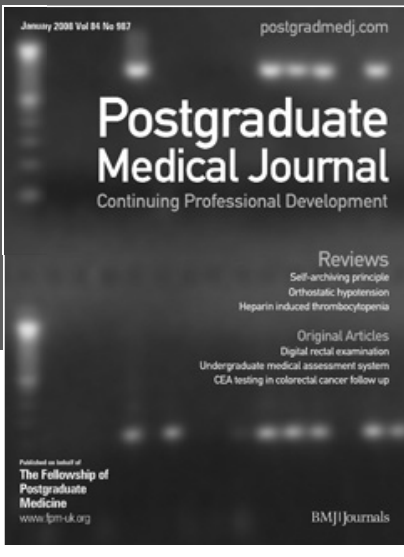

postgradmedj.com

BMJIJournals 


\section{Visceral hypersensitivity in endometriosis: a new target for treatment?}

B Issa, T S Onon, A Agrawal, et al.

Gut 2012 61: 367-372 originally published online August 25, 2011

doi: 10.1136/gutjnl-2011-300306

Updated information and services can be found at:

http://gut.bmj.com/content/61/3/367.full.html

\section{These include:}

References This article cites 51 articles, 11 of which can be accessed free at: http://gut.bmj.com/content/61/3/367.full.html\#ref-list-1

Email alerting Receive free email alerts when new articles cite this article. Sign up in service the box at the top right corner of the online article.

Topic Articles on similar topics can be found in the following collections

Collections

Irritable bowel syndrome (252 articles)

Notes

To request permissions go to:

http://group.bmj.com/group/rights-licensing/permissions

To order reprints go to:

http://journals.bmj.com/cgi/reprintform

To subscribe to BMJ go to:

http://group.bmj.com/subscribe/ 